\title{
Evaluation of investment effect of urbanization construction based on system dynamics model \\ -- Taking Guizhou Province as an example
}

\author{
Chenggang Li, Yandan Xue ${ }^{\text {, }}$, Xiaoliang Liu, Lingyun Luo, Mingguo Zhang, \\ Wulin Zhang, Ke Xu \\ Faculty of Finance, Guizhou University of Finance and Economics, Guiyang, China \\ a1532895790@qq.com
}

Keywords: system dynamics model; urbanization; investment effect; evaluation

\begin{abstract}
. evaluating the effect of urbanization construction investment is conducive to the understanding of the effect of urbanization construction investment, to determine the feasibility of urbanization construction investment and investment projects in the direction of the focus. Taking Guizhou Province as an example, this paper makes a deep study on the effect of urbanization construction by using the annual data of 2010-2015 in Guizhou Province, using the system dynamics model. The results showed that the amount of investment and GDP showed the trend of mutual promotion growth. The increase of GDP is beneficial to the increase of the total output value of the construction industry, so as to increase the urban construction area and construction area of Guizhou Province, and improve the urbanization process of Guizhou Province. Investment in the process of urbanization has a positive effect on it, but the effect is not very obvious.
\end{abstract}

\section{Introduction}

In the process of urbanization development, Guizhou Province needs a large number of investment to complete it. Through the evaluation of Guizhou Province urbanization construction investment, we can understand the effect of investment of urban construction, and learn the causal relationship between urbanization and investment.

Many scholars have studied on the relationship between urbanization and investment, as well as the investment mechanism of urbanization. Rao and Bird (2012) believe that the urbanization infrastructure construction in India requires a lot of investment, the financing channels of investment funds are mainly from local borrowing, the collection of residential development costs, the sale of land and other assets, public-private partnership model. Using the annual data from 1987 to 2010, H. Jing (2013) uses the vector error correction model to empirically analyze the dynamic relationship between urbanization and investment. The empirical results show that, there exists a long-term equilibrium relationship between urbanization level and investment. By constructing VAR model, C. Min and J. Liu (2013) empirically research the relationship between population urbanization and financial investment in capital construction. The empirical results show that the long-term accumulation effect of financial investment in basic construction on the population urbanization is weak, and the adjustment effect is not obvious. Using the panel data of China's 31 Provinces, B. Lin (2014) utilizes the PVAR model to study the interactive effects of government public investment, private investment and urbanization. The empirical results show that the government public investment and private investment in eastern, central and western China have little impact on urban residents per capital income. From the two subjects of government investment and private investment, J. Wu et al (2016) analyzes their influence on urbanization. They think that the government investment scale and monopoly lead to China's urban level increased significantly, and the impact of private investment on the urbanization development is more direct.

From the above scholars' research results, it can be found that the existing scholars have not yet deeply studied the evaluation of the investment effect of urbanization. In this paper, using the system dynamics model, taking Guizhou Province as an example, the paper uses the data of Guizhou Province to evaluate the investment effect of urbanization. 


\section{Structural Analysis}

In the evaluation system of investment effect on urbanization, we divide the system into two subsystems: (1) the investment subsystem; (2) the evaluation subsystem of urbanization. These two subsystems interact with each other. Among them, the core of the whole system is the evaluation subsystem of urbanization. The system aims at evaluation the investment effect in the process of the urbanization. We can use the construction of infrastructure (such as: growth in the proportion of housing construction area, urban construction land, urban population) and Guizhou Province GDP factors to make the comparison. Then, using the comparison, we can get the result between the investment and capital efficiency of urbanization. Thereby, we establish a system dynamics model to assess the effect of investment.

Urbanization subsystem. As the main system of this model, the process of urbanization in Guizhou Province is mainly studied. Through the growth of GDP to promote the construction industry's GDP increased, thus affecting the urban population in Guizhou Province, housing construction area, urban construction area, to consider the degree of urbanization in Guizhou Province. At the same time, per capital housing area and per capital urban construction area can reflect the development of urbanization. The dynamic model of urbanization subsystem is shown in Figure 1.

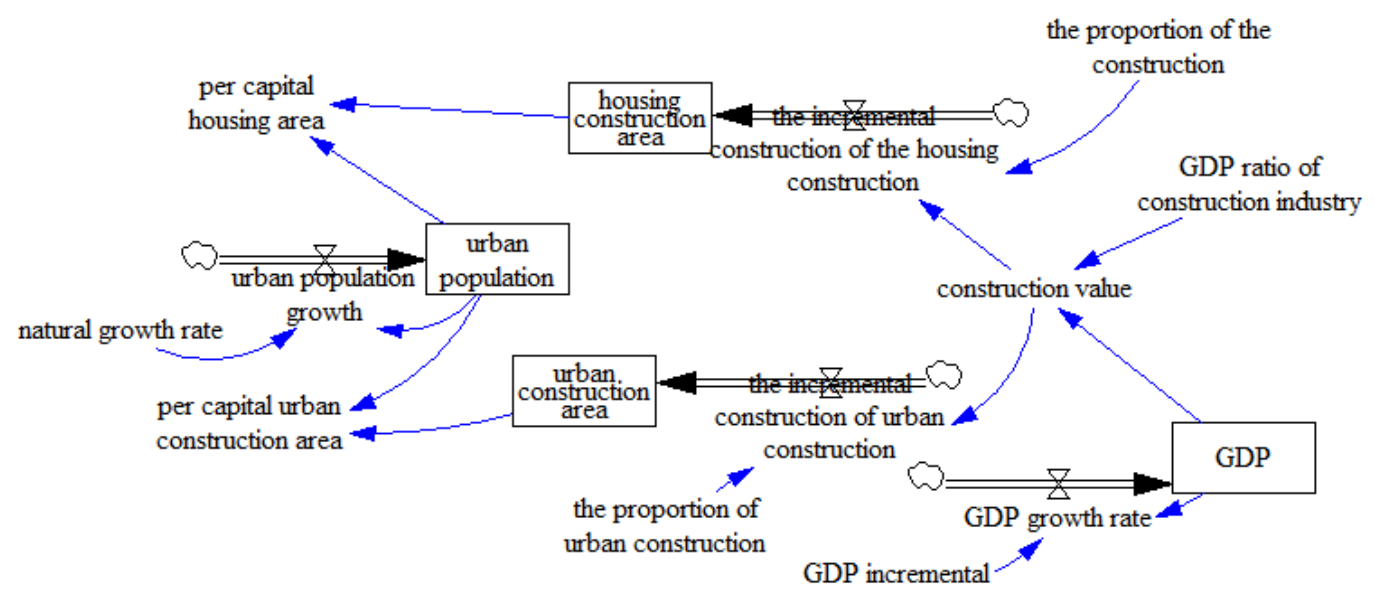

Fig. 1 dynamic model of urbanization subsystem

Urbanization subsystem dynamics model equations are shown as the follows:

a.GDP=INTER (GDP increment, 4062.16)

b.GDP incremental $=$ GDP growth rate $*$ GDP

c.urban population growth $=$ natural growth rate $*$ urban population

d. the incremental construction of urban construction $=$ the proportion of urban construction * construction value

e. the incremental construction of the housing construction $=$ the proportion of the construction * construction value

f. construction value $=$ GDP ratio of construction industry $*$ GDP

g. per capital housing area $=$ housing construction area / urban population

h. per capital urban construction area = urban construction area / urban population

i. the construction area of housing construction =INTER (housing construction incremental, 14456)

j.urban population =INTER (urban population growth, 1176.25)

k. urban construction area =INTER (urban construction increment, 1002.15)

Investment subsystem. Urbanization-related investment mainly stats budget funds, domestic loans, foreign investment, self-financing and other funds. These investment constitute total social investment, thereby forming a GDP of Guizhou Province. System dynamics model shown in Figure 2. 


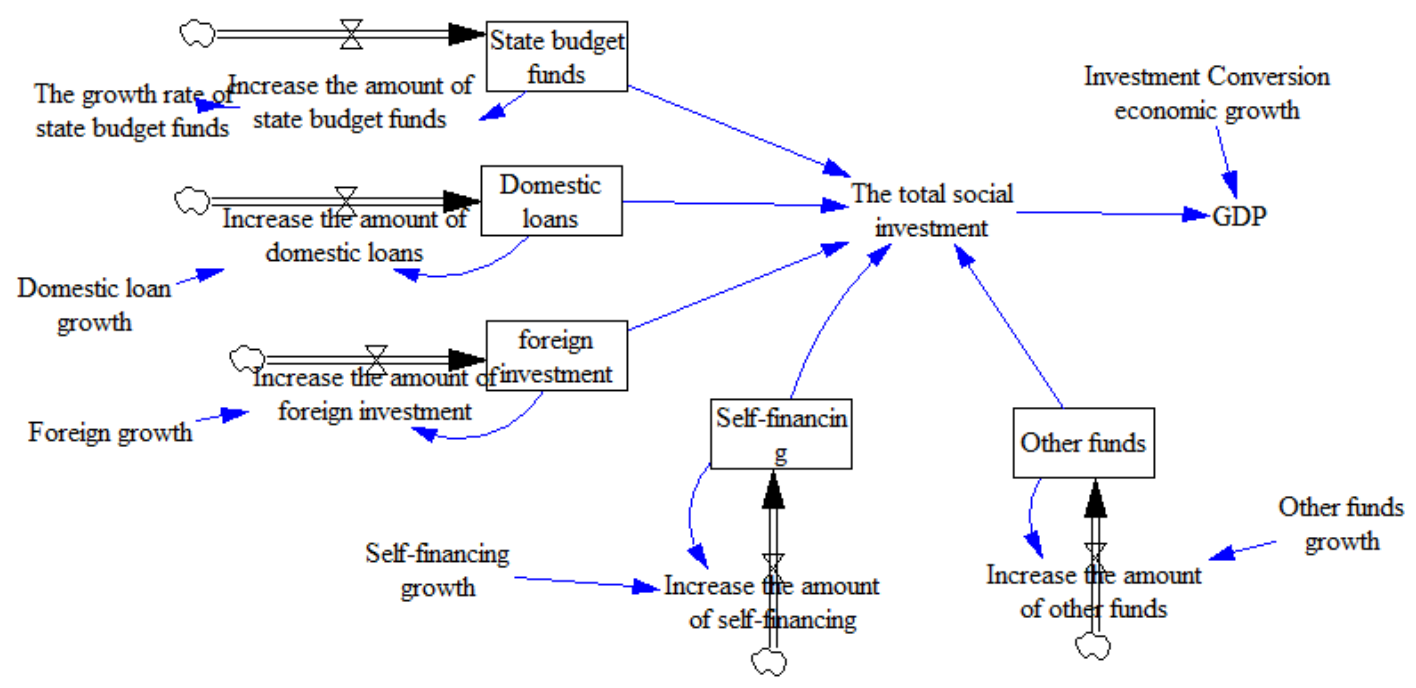

Fig. 2 dynamic model of investment subsystem

Investment subsystem system dynamics model equations are as follows:

a. Increase the amount of state budget funds $=$ The growth rate of state budget funds * State budget funds

b. Increase the amount of domestic loans= Domestic loan growth * Domestic loans

c.Increase the amount of foreign investment= Foreign growth * foreign investment

e. Increase the amount of self-financing= Self-financing growth * Self-financing

f. Increase the amount of other funds= Other funds growth * Other funds

g. The total social investment $=$ State budget funds + Domestic loans + foreign investment+Self-financing+Other funds

h. State budget funds= INTER(Increase the amount of state budget funds,292.1)

i. Domestic loans= INTER(Increase the amount of domestic loans,897.3)

j. Foreign investment= INTER (Increase the amount of foreign investment,11.4)

k. Self-financing= INTER(Increase the amount of other funds,1822.6)

l. Other funds= INTER(Increase the amount of other funds,620.7)

$\mathrm{m}$. GDP=Investment Conversion economic growth * The total social investment

\section{The simulation model and analysis}

Urban indicators simulation curve. Housing construction area simulation curve is shown in Figure 3. Urban population simulation curve is shown in Figure 4.

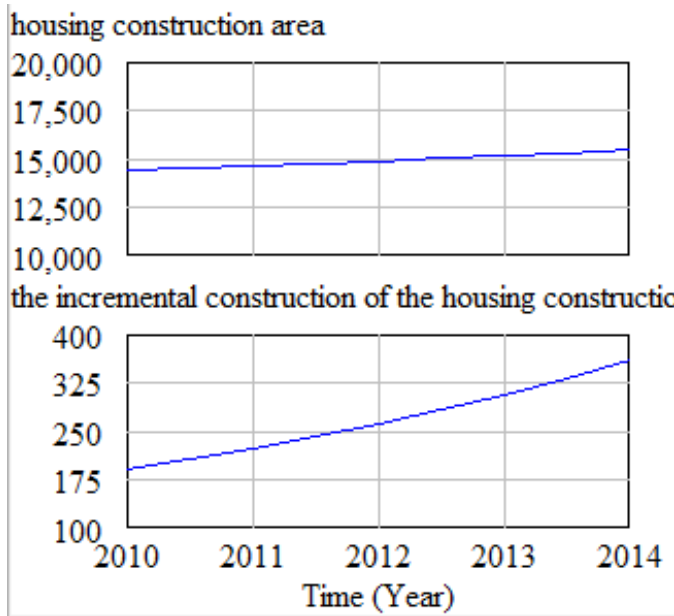

Fig. 3 housing construction area

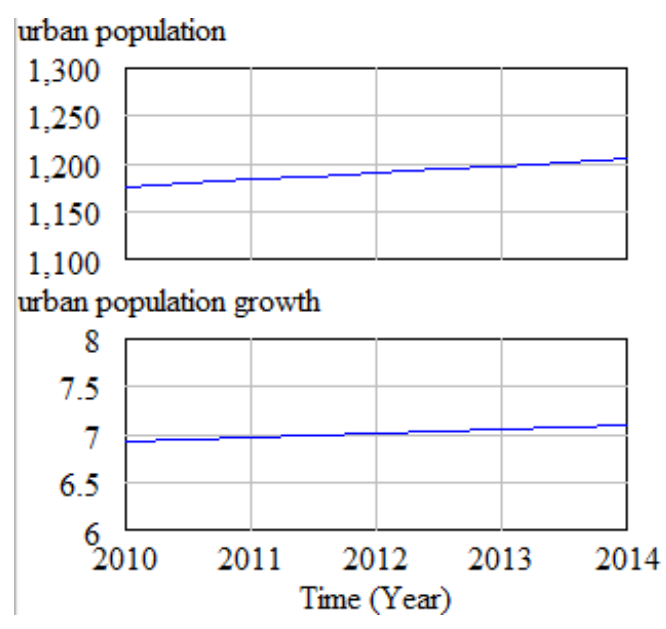

Fig. 4 urban population

Urban construction area simulation curve is shown in Figure 5. GDP simulation curve is shown in Figure 6. 


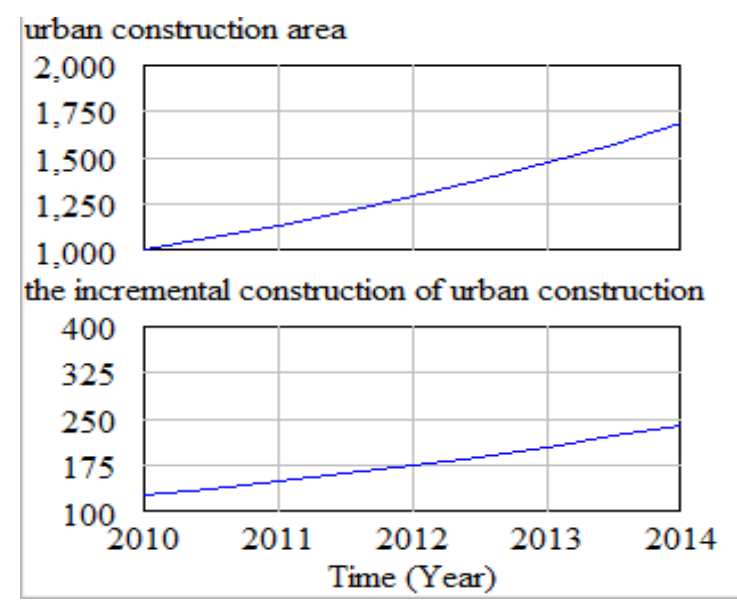

Fig. 5 urban construction area

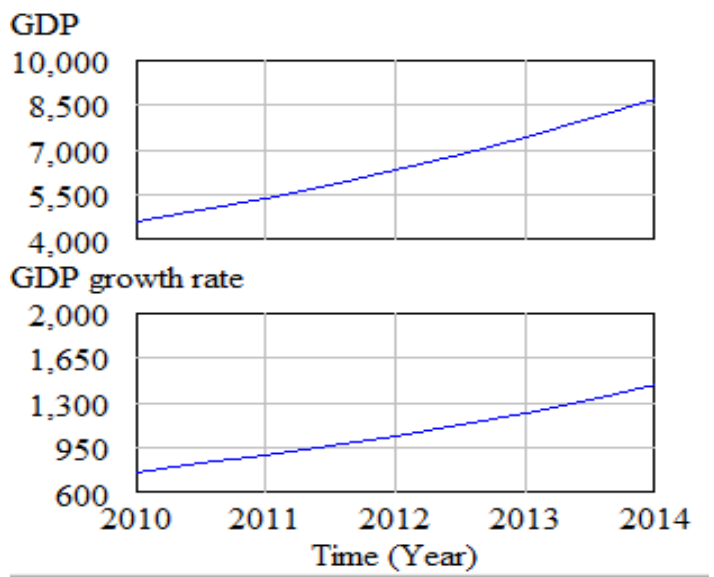

Fig. 6 GDP

Simulation curve of the total social investment funds, and the total investment in GDP and social simulation curve are shown in Figure 7.
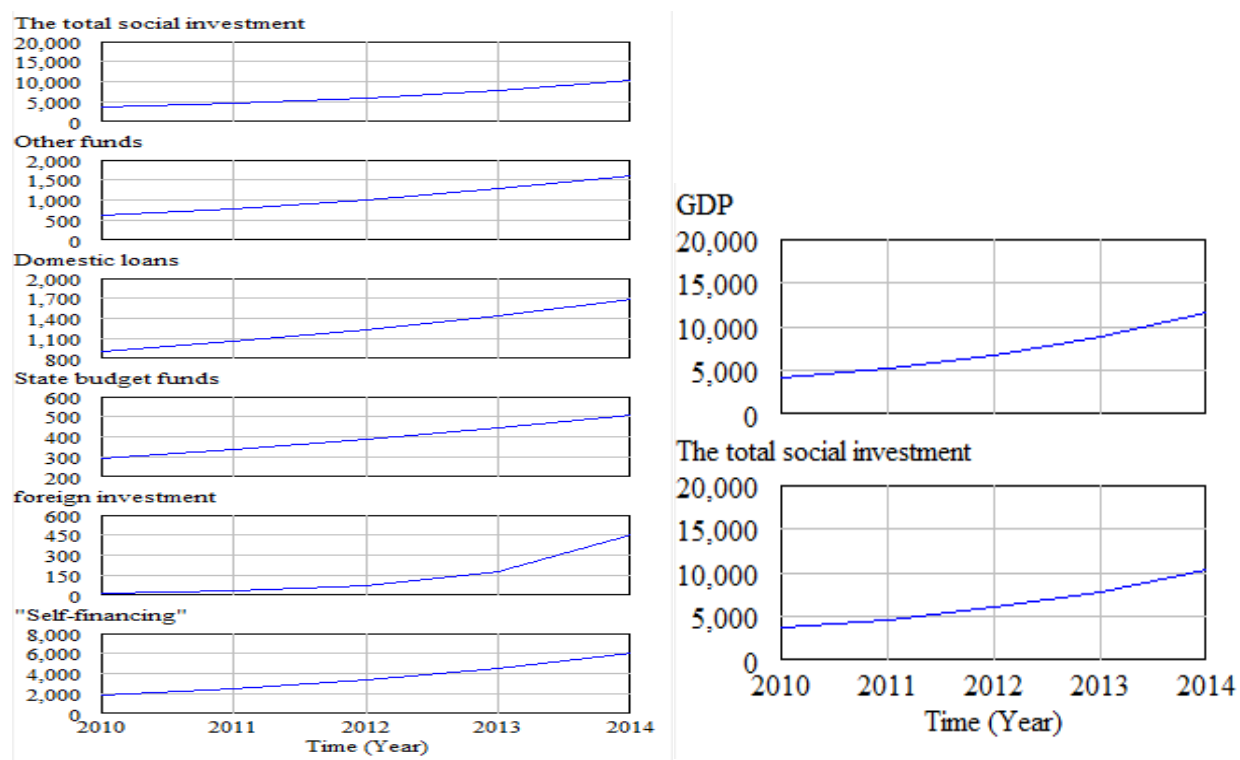

Fig. 7 total social investment

As can be seen from Figure 4 to Figure 8, the investment in fixed assets in Guizhou Province has increased year by year. The various investment forms such as the national budget funds, foreign investment, self-financing, loans and other domestic sources of funds make the total social investment increase. This helps improve the GDP growth in Guizhou Province. But the growth rate of GDP is slower than the previous year's overall investment rate. Overall, there is a growth trend that the investment and GDP is interaction. This indicates that an increase in investment is in favor of an increase in GDP. Also, the increase in GDP is in favor of the construction of the GDP increase, thereby increasing urban construction area and housing construction area. This promotes the development of urbanization in Guizhou Province. However, the growth rate is not fast. In the system dynamics model of urbanization construction investment evaluation, we can see that the increase in total social investment is in favor of growth of GDP of Guizhou Province. The increase in GDP is in favor of increasing construction output, which increase urban construction area and housing construction area of Guizhou Province, and increasing urbanization in Guizhou Province. So, the investment promotes the process of urbanization, but the effect is not obvious.

\section{Conclusion}

Using the 2010 - 2015 annual data of the Guizhou Province, this paper utilizes system dynamics model to study the investment effect of urban construction. The results show that there is a growth trend that the investment and GDP is interaction. The increase in GDP is in favor of the increase in 
construction output, thereby increasing the area of urban construction and housing construction area of Guizhou Province, and increasing urbanization Guizhou Province. So, the investment promotes the process of urbanization, but the effect is not obvious.

\section{References}

[1] M. G. Rao, R. M. Bird, Coping with change: the need to restructure urban governance and finance in India, University of Toronto, Institute on Municipal Finance and Governance in its series IMFG Papers with number 04, 2012.

[2] H. Jing, An empirical study on the dynamic effects of urbanization and investment relations between the VEC model, Special Zone Economy. 3 (2013) 187-189.

[3] M. Han, J. Liu, Effect of public infrastructure investment urbanization - An empirical analysis based on VAR model, Urban Problems. 12 (2013) 62-67.

[4] B. Lin. Research on interactive effects of urbanization public investment and private investment based on PVAR model, Fiscal Studies, 3 (2014) 72-75.

[5] J. Wu, Y. Ai, F. Zhang, Government investment, private investment difference on the effects of urbanization development analysi, Inquiry into Economic Issues. 3 (2016) 76-85. 